\title{
Pengaruh Penggunaan Bahan Limbah Polimer Sebagai Campuran Aspal Modifikasi Terhadap Kinerja Marshall
}

\author{
Indah Handayasari $^{1}$; Irma Sepriyanna ${ }^{2}$; Dyah Pratiwi Kusumastuti ${ }^{3}$ \\ ${ }^{1,2,3}$ Institut Teknologi PLN \\ ${ }^{1}$ Indah.handayasari@itpln.ac.id
}

\begin{abstract}
One of the polymer materials that can be a mixture of asphalt is Ethylene Vinyl Acetate, which is a material that is widely used in making toys and making footwear. This large amount of toys and footwear production waste has only become rubbish and has not been utilized optimally. Ethylene Vinyl Acetate polymers themselves belong to elastomeric polymers which have flexible properties such as rubber, smooth, flexible, resistant to low temperatures, are not easily cracked and are resistant to water. The use of polymer material as a mixture of asphalt has been widely carried out considering that asphalt modification with polymeric materials is known from several tests showing that it has better resistance to deformation and overcoming cracks, so that road construction can be produced more durable and can reduce maintenance and repair costs Street. In this study the use of Ethylene Vinyl Acetate waste on asphalt mixes has a pretty good effect, this is seen from the results of marshall tests that can meet the requirements.
\end{abstract}

Keywords: Waste, Ethylene Vinyl Acetate, Marshall

\begin{abstract}
ABSTRAK
Salah satu bahan polimer yang dapat menjadi campuran aspal yaitu Ethylene Vinyl Acetate.yang merupakan bahan yang banyak digunakan dalam pembuatan mainan dan pembuatan alas kaki. Limbah hasil produksi mainan dan alas kaki yang cukup banyak ini hanya menjadi sampah dan belum termanfaatkan secara optimal. Polimer ethylene vinyl acetate sendiri tergolong pada polimer elastomer yang memiliki sifat lentur seperti karet, halus, fleksibel, tahan terhadap suhu rendah, tidak mudah retak dan tahan terhadap air. Penggunaan bahan polimer sebagai campuran aspal telah banyak dilakukan mengingat aspal modifikasi dengan bahan polimer diketahui dari beberapa pengujian menunjukkan bahwa memiliki hasil ketahanan yang lebih baik terhadap deformasi serta mengatasi keretakan-keretakan, sehingga dapat dihasilkan pembangunan jalan lebih tahan lama serta dapat mengurangi biaya perawatan maupun perbaikan jalan. Pada penelitian ini penggunaan limbah ethylene vinyl acetate terhadap campuran beraspal memberikan pengaruh yang cukup baik, hal ini dilihat dari hasil pengujian marshall yang dapat memenuhi ketentuan yang disyaratan.
\end{abstract}

Kata kunci: Limbah, Ethylene Vinyl Acetate, Marshall 


\section{JURNAL FORUM MEKANIKA}

Vol. 9, No. 1, Mei 2020, P-ISSN: 2356-1491, E-ISSN: 2655-8211

DOI: https://doi.org/10.33322/forummekanika.v9i1.1098

\section{PENDAHULUAN}

Kerusakan konstruksi perkerasan jalan dapat terjadi dikarenakan banyak hal, baik dari perencanaan awal, pelaksanaan pekerjaan maupun saat jalan dibuka untuk menerima beban lalu lintas. Beberapa faktor yang dapat menyebabkan terjadinya kerusakan konstruksi pada perkerasan lentur antara lain adalah pertumbuhan volume lalu lintas yang tidak sama dengan perkiraan yang direncanakan, beban kendaraan yang melebihi batas maksimum yang diizinkan dan material yang digunakan sebagai bahan lapisan struktur perkerasan yang tidak tepat. Meskipun perkerasan telah direncanakan dengan sangat baik, pada kenyataannya tidak sesuai dengan kondisi yang ada dilapangan, dimana kondisi perkerasan seringkali telah mengalami kerusakan sebelum masa layan rencana dari jalan tersebut habis ${ }^{[1]}$

Material yang digunakan dalam campuran perkerasan baik aspal, agregat kasar, agregat halus serta filer sangat menentukan kualitas konstruksi perkerasan lentur tersebut. Salah satu material penting dalam struktur perkerasan lentur yaitu aspal. Salah satu cara untuk mendapatkan kualitas aspal yang baik dengan melakukan melakukan modifikasi terhadap campuran aspal. Campuran aspal diberikan bahan tambahan untuk meningkatkan kualitas kinerjanya. Selain itu dengan menggunakan bahan tambah atau aditif pada campuran aspal, tetap dapat meningkatkan stabilitas walaupun mengurangi jumlah kebutuhan aspal. ${ }^{[2]}$

Berkembangnya ilmu pengetahuan dan teknologi, bahan polimer yang sering digunakan dalam produksi perkerasan jalan adalah modifier aspal. Bahan aditif berjenis polimer yang ditambahkan dalam jumlah kecil ke dalam aspal terbukti dapat meningkatkan kinerja aspal dan memperpanjang umur kekuatan/masa layanan perkerasan tersebut. Polimer dapat meningkatkan daya tahan perkerasaan terhadap berbagai kerusakan, seperti deformasi permanen, retak akibat perubahan suhu, fatigue damage, serta pemisahan atau pelepasan material ${ }^{[3]}$. Hal ini dapat dilihat dari hasil penelitian ${ }^{[4]}$, yang menunjukkan hasil bahwa aspal modifikasi ethylene vinyl acetate menghasilkan nilai stabilitas marshall lebih besar yaitu $1634,57 \mathrm{Kg}$ dan $1361,95 \mathrm{Kg}$ untuk campuran tanpa modifikasi ethylene vinyl acetate. Selain itu nilai modulus resilient campuran yang lebih besar juga dihasilkan oleh campuran yang menggunakan aspal modifikasi ethylene vinyl acetate. Nilai total deformasi terkecil $\left(0,75 \mathrm{~mm}\right.$ pada temperature $\left.45^{\circ} \mathrm{C}\right)$ juga dihasilkan oleh campuran yang menggunakan aspal modifikasi ethylene vinyl acetate sehingga memberikan kinerja yang baik khususnya dalam mengatasi deformasi. Penelitian lain yang dilakukan ${ }^{[5]}$ memberikan hasil bahwa aspal modifikasi ethylene vinyl acetate memiliki rongga udara yang lebih kecil daripada aspal penetrasi 60/70 karena memiliki kepadatan yang besar. Rongga udara yang rendah dalam agregat pada aspal modifiasi ethylene vinyl acetate dikarenakan rongga di dalam agregat yang makin padat diisi oleh aspal modifikasi ethylene vinyl acetate. Campuran yang mempunyai nilai kepadatan yang tinggi akan memiliki kemampuan untuk menahan beban yang lebih besar dibandingkan dengan campuran yang memiliki kepadatan rendah ${ }^{[6]}$.

Penambahan bahan untuk menaikan mutu aspal diketahui memiliki dua cara, yaitu dengan cara basah dan cara kering. Tentu keduanya memiliki cara penambahan yang berbeda. Cara basah, bahan tambah dicampur dalam aspal panas secara langsung dengan suhu tertentu serta dicampur hingga homogen. Sedangkan cara kering, yaitu dicampur dengan agregat secara langsung dengan suhu tertentu dan diaduk hingga homogen ${ }^{[7]}$.

Pada penelitian ini limbah Ethylene Vinyl Acetate digunakan sebagai bahan tambah terhadap campuran beraspal. Limbah jenis ini digunakan mengingat ethylene vinyl acetate merupakan limbah polimer serta termasuk limbah anorganik dan sulit terurai yang ditambahkan dengan campuran beraspal baik menggunakan cara kering maupun cara basah, lalu keduanya dibandingkan 
berdasarkan hasil kualitasnya melalui uji marshall. Diharapkan dari penelitian ini mampu memberikan hasil yan baik serta menjadi alternatif pemanfaatan limbah polimer yang dapat digunakan pada bidang konstruksi.

\section{METODE/PERANCANGAN PENELITIAN}

\subsection{Kerusakan Perkerasan Jalan}

Kerusakan perkerasan jalan merupakan kondisi dimana telah terjadinya kerusakan pada konstruksi perkerasan sebelum mencapai masa layanan yang direncanakan. Kerusakanyang terjadi baik secara fungsional dan struktural akan menimbulkan banyak kerugian. Hal ini dapat menimbulkan ketidak nyamanan bagi pengguna jalan bahkan dapat menibulkan terjadinya kecelakaan lalu lintas yang diakibatkan kerusakan pada struktur perkerasan. Kerusakan perkerasan dapat disebabkan oleh pengaruh kondisi lingkungan diantaranya kondisi lapisan tanah dasar yang tidak stabil, beban lalu lintas yang melampaui batas yang ditentukan, pemilihan material penyusun perkerasan yang tidak sesuai dan lainnya.

\subsection{Perkerasan Lentur (Flexible Pavement)}

Aspal berfungsi sebagai bahan pengikat pada perkerasan jalan lentur. Aspal dapat didefinisikan sebagai material semen yang berwarna hitam, dengan memiliki tekstur padat atau setengah padat. Umumnya, jenis aspal yang digunakan di Indonesia adalah jenis aspal dengan penetrasi 60/70 atau dengan penetrasi 80/100. Jenis ini lebih cocok dengan iklim di Indonesia ${ }^{[8]}$. Dalam penggunaannya, terlebih dahulu aspal dipanaskan mencapai temperatur tertentu sehingga aspal menjadi cair. Dalam kondisi cair, aspal bisa menutupi dan mengikat partikel agregat serta masuk ke pori-pori lapisan jalan. Saat temperaturnya sudah menurun, aspal akan menjadi lebih keras kemudian mengikat agregat pada lokasi yang sama.

\subsection{Ethylene Vinyl Acetate}

Ethylene vinyl acetate merupakan polimer elastomer yang memiliki sifat lentur seperti karet, halus, fleksibel, tahan terhadap suhu rendah, tidak mudah tretak, tahan terhadap air, dan memiliki resistensi terhadap radiasi UV. Ethylene vinyl acetate memiliki bau seperti cuka yang khas dan kompetitif dengan produk karet dan vinil polimer pada alat - alat listrik. Salah satu bahan polimer yang dapat ditambahkan adalah ethylene vinyl acetate. Pada saat ini bahan ethylene vinyl acetate telah banyak dimanfaatkan pada indusri kebutuhan rumah tangga, peralatan olahraga dan juga konstruksi jalan raya. Limbah ethylene vinyl acetate foam yang dimanfaatkan sebagai bahan campuran aspal polimer, sebelumnya berbentuk lembaran. Eva jenis foam memiliki titik leleh pada suhu kurang dari $72^{\circ} \mathrm{C}$ dan Berat jenis $1,1 \mathrm{gr} / \mathrm{cm}^{3}$. Agar dapat tercampur dengan baik, maka bahan ethylene vinyl acetate yang sebelumnya berbentuk lembaran perlu dilakukan pengecilan ukuran, yaitu sesuai ketentuan ukuran butir Bina Marga divisi 6 revisi 3 sebesar kurang dari 9,5mm.

\subsection{Tahapan Penelitian}

Material utama yang digunakan dalam penelitian ini adalah aspal penetrasi 60/70, agregat kasar, agregat halus, filler semen portland serta bahan tambah limbah ethylene vinyl acetate jenis foam terhadap campuran beraspal. Limbah ethylene vinyl acetate digunakan sebagai bahan tambah pada campuran beraspal dengan cara kering maupun cara basah, lalu keduanya dibandingkan berdasarkan hasil kualitasnya melalui uji marshall. Metode Pengumpulan data diperoleh dengan parameter stabilitas marshall, flow, VIM (Void in Mixture), VMA (Void In Mineral Aggregate), 


\section{JURNAL FORUM MEKANIKA}

Vol. 9, No. 1, Mei 2020, P-ISSN: 2356-1491, E-ISSN: 2655-8211

DOI: https://doi.org/10.33322/forummekanika.v9i1.1098

VFA (Void In Filled with Asphalt). Setelah dilakukan pendataan dilaboratorium, pengelolaan data dan analisis berdasarkan data yang telah diperoleh sehingga didapatkan hasil pemecahan masalah yang efektif dan terarah.

\section{HASIL DAN PEMBAHASAN}

Berdasarkan hasil pengujian Marshall didapat nilai-nilai untuk mengetahui variasi optimum campuran, yaitu Kelelehan (flow), Stabilitas (stability), VIM (Void in Mixture), VMA (Void In Mineral Aggregate) dan juga VFA (Void In Filled with Asphalt). Dari hasil data yang didapatkan terhadap pencampuran bahan tambah ethylene vinyl acetate dengan cara basah dan cara kering memberikan hasil yang bahwa tidak semua nilai dari karakteristik marshall dapat terpenuhi sesuai nilai persyaratan yang ditentukan. Adapun hasil pengujian marshall untuk setiap variasi sebagai berikut :

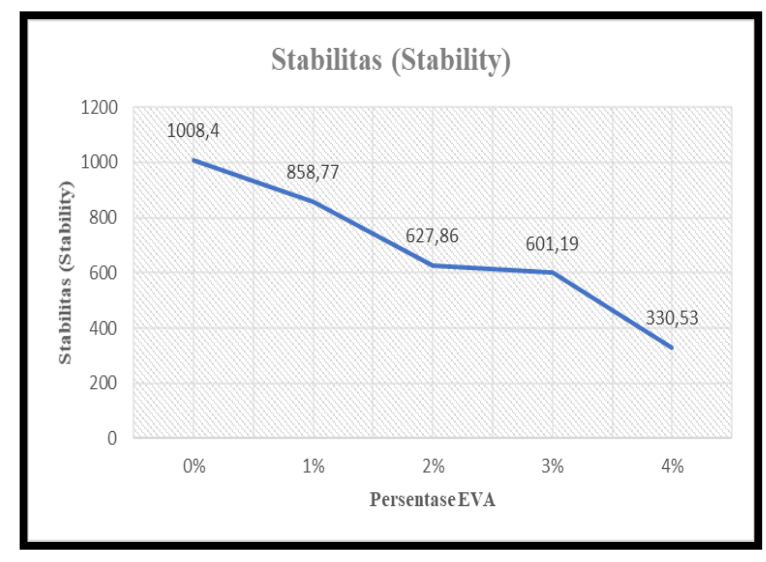

(a) Cara Kering

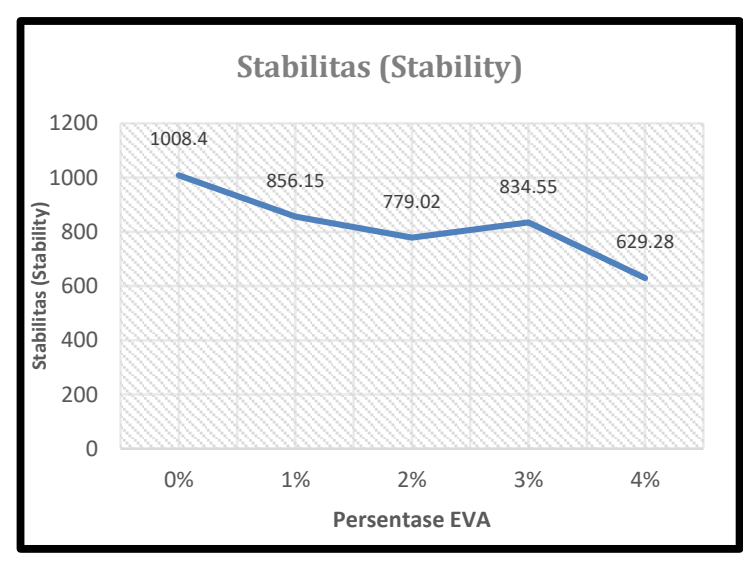

(b) Cara Basah

Gambar 1. Nilai Stabilitas

Berdasarkan hasil pengujian stabilitas yang dilakukan untuk kelima persentase bahan tambah limbah ethylene vinyl acetate dengan cara kering maupun cara basah yang dapat memenuhi persyaratan nilai stabilitas adalah variasi $0 \%$ yaitu sebesar $1008,4 \%$ serta cara kering untuk variasi $1 \%$ sebesar $858,77 \%$ dan untuk cara basah variasi $1 \%$ sebesar $856,15 \%$. Stabilitas merupakan kemampuan lapis perkerasan untuk menahan deformasi akibat beban lalu lintas yang bekerja di atasnya, tanpa mengalami perubahan bentuk seperti gelombang dan alur. Nilai stabilitas dipengaruhi oleh gesekan antar butiran agregat (internal friction), penguncian antar butir agregat (interlooking) dan daya ikat yang baik dari lapisan aspal (koreksi), disamping itu proses pemadatan, mutu agregat, dan kar aspal juga berpengaruh ${ }^{[9]}$. Ketidak optimuman dari fungsi agregat memberi pengaruh terhadap kestailan benda uji. 


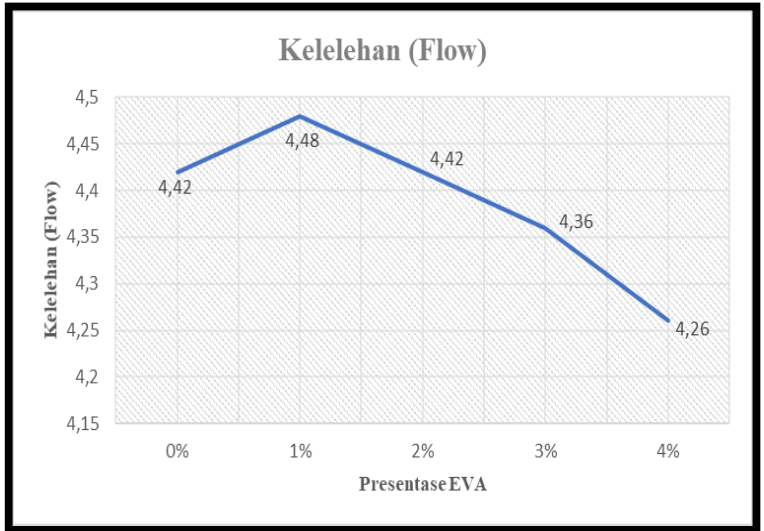

(a) Cara Kering

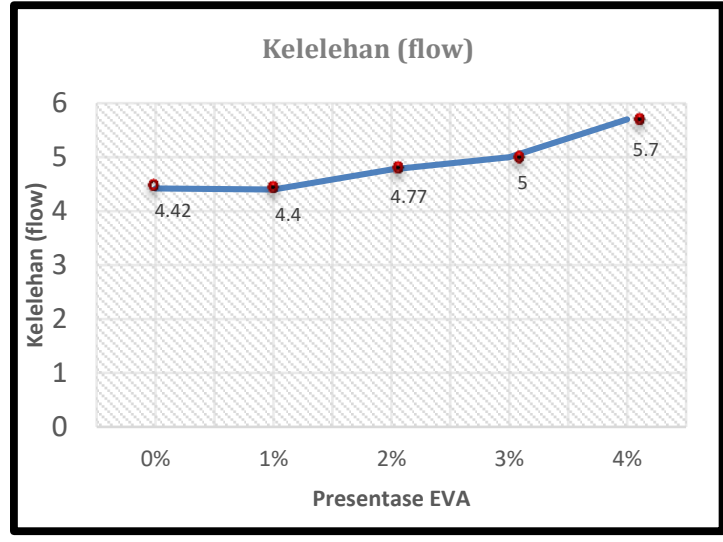

(b) Cara Basah

Gambar 2. Nilai Kelelehan

Dilihat dari hasil grafik nilai flow menunjukkan bahwa nilai flow tertinggi terdapat pada kadar campuran polimer $1 \%$ yaitu sebesar $4,48 \mathrm{~mm}$ dengan pencampuran bahan limbah ethylene vinyl acetate dengan cara kering. Nilai flow semakin menurun seiring dengan bertambahnya persentase kadar limbah ethylene vinyl acetate dengan cara kering terhadap campuran beraspal. Berdasarkan hasil grafik yang dihasilkan untuk campura menggunakan cara basah didapatkan nilai flow tertinggi terdapat pada kadar campuran polimer $4 \%$ dengan nilai sebanyak $5,7 \mathrm{~mm}$. Sedangkan jika ditinjau dari persyaratan yang ditentukan untuk nilai flow yaitu sebesar $2-4 \mathrm{~mm}$, maka nilai flow tidak ada yang memenuhi spesifikasi.

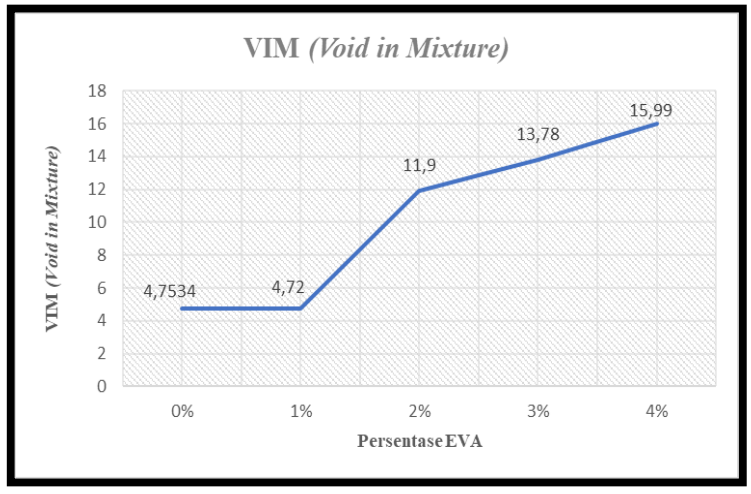

(a) Cara Kering

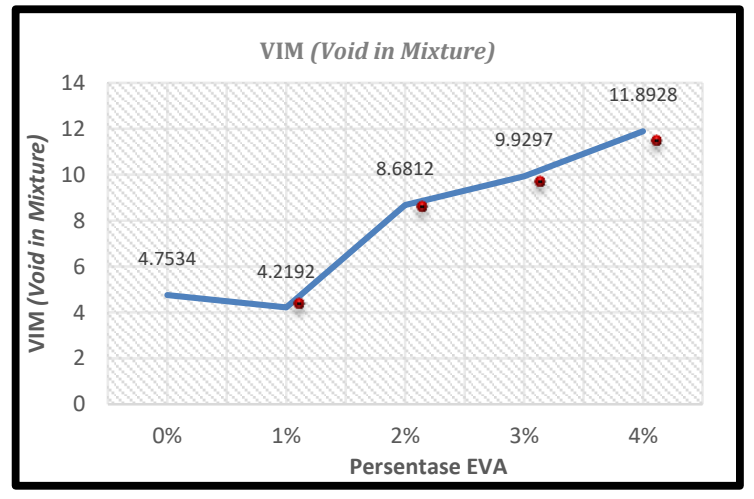

(b) Cara Basah

Gambar 3. Nilai VIM

Berdasarkan hasil pengujian, nilai VIM yang memenuhi pada persentase variasi $0 \%$ sebesar $4,753 \%$ dan variasi kadar limbah ethylene vinyl acetate dengan cara kering yaitu dengan persentase $1 \%$ sebesar $4,72 \%$. Untuk cara basah, nilai VIM yang memenuhi juga pada persentase variasi $1 \%$ sebesar 4,2192 \%, dimana persyaratan spesifikasi yang ditentukan yaitu sebsar $3-5 \%$. Faktor yang dapat mempengaruhi nilai VIM adalah kepadatan benda uji ketika dilakukan pemadatan dengan tumbukan dan rongga udara didalam campuran. 


\section{JURNAL FORUM MEKANIKA}

Vol. 9, No. 1, Mei 2020, P-ISSN: 2356-1491, E-ISSN: 2655-8211

DOI: https://doi.org/10.33322/forummekanika.v9i1.1098

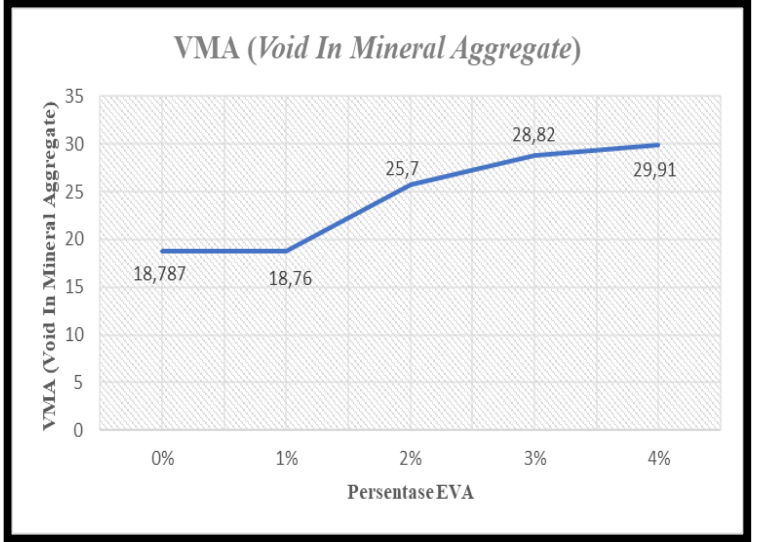

(a) Cara Kering

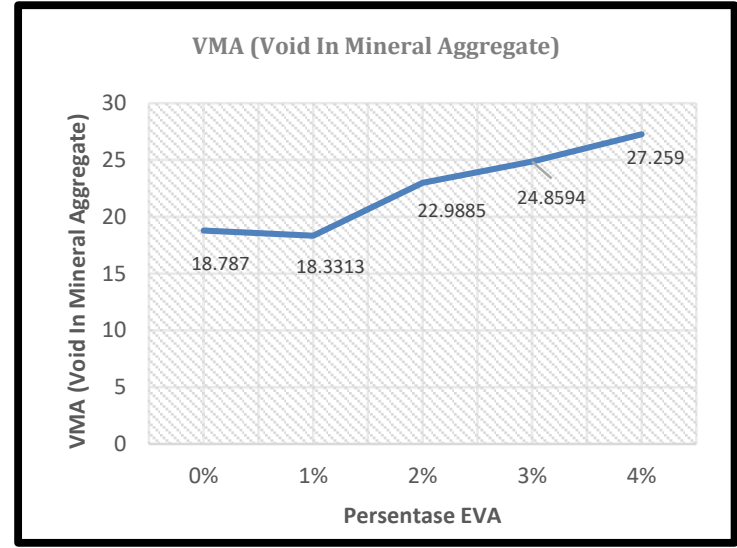

(b) Cara Basah

Gambar 4. Nilai VMA

Berdasarkan hasil pengujian didapatkan semua variasi persentase bahan tambah ethylene vinyl acetate memunuhi ketentuan spesifikasi yang disyaratkan sebesar $>15$.

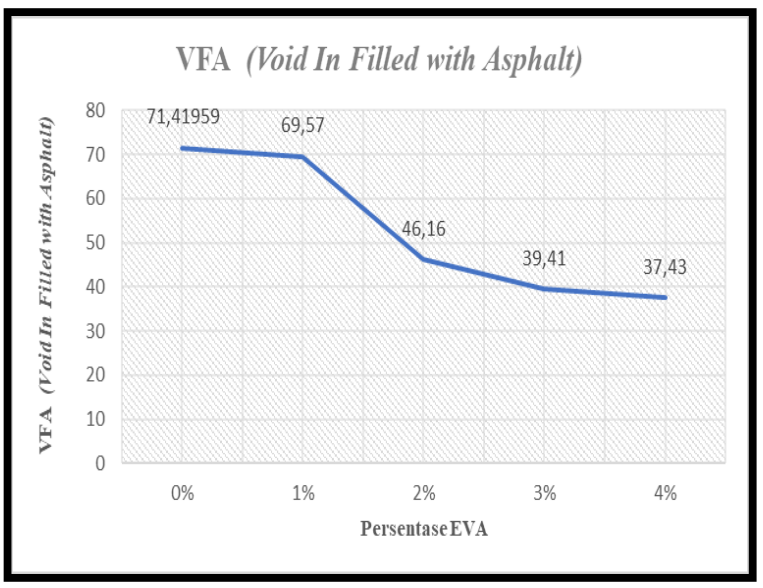

(a) Cara Kering

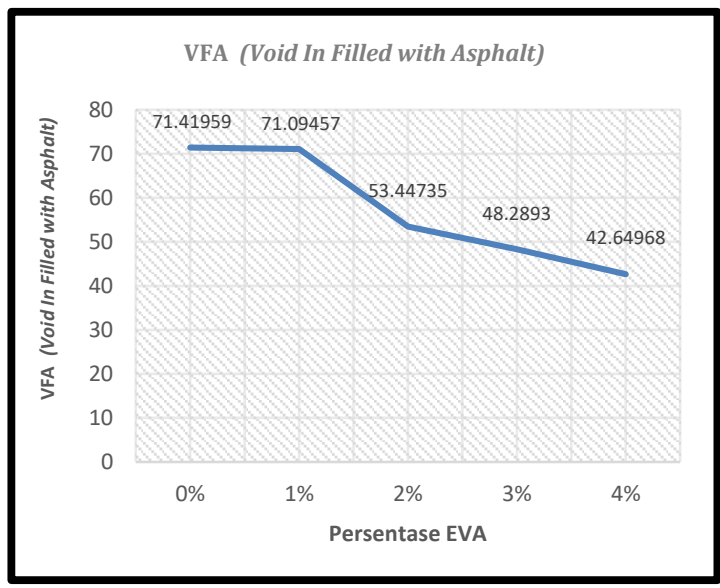

(b) Cara Basah

Gambar 5. Nilai VFA

Berdasarkan hasil dari pengujian yang dilakukan, nilai VFA dengan nilai minimum 65 , variasi yang dapat memenuhi spesifikasi adalah pada persentase $0 \%$ dan juga $1 \%$ untuk pencanmpuran menggunakan cara kering maupun cara basah. Hasil nilai stabilitas, flow, VIM, VFA, VMA, pada pengujian karakteristik marshall pencampuran limbah ethylene vinyl acetate menggunakan cara kering maupun cara basah, maka nilai optimum campuran asphalt concrete wearing course pada variasi bahan tambah dengan persantase $1 \%$ ethylene vinyl acetate.

\section{KESIMPULAN DAN SARAN}

Secara umun simpulan pada penelitian ini dapat disimpulkan bahwa nilai VMA (Void In Mineral Aggregate) memenuhi semua standar ketentuan. Sedangkan untuk hasil nilai dari karakteristik marshall selain dari nilai VMA, hanya pada prosentase $1 \%$ saja yang dapat memenuhi standar ketentuan baik nilai stabilitas, flow, VIM maupun VFA baik menggunakan cara kering maupun cara basah. 


\section{UCAPAN TERIMAKASIH}

Ucapan terima kasih kami tujukan kepada LPPM Institut Teknologi PLN yang telah memfasilitasi penelitian ini dalam skema pendanaan Penelitian Dosen Pemula Tahun Ajaran 2019/2020 serta semua pihak yang ikut membantu pada proses pelaksanaan maupun penyusunan laporan dan naskah jurnal.

\section{DAFTAR PUSTAKA}

[1] V. A. P. I. W. D. S. Putra, "Identifikasi Jenis Kerusakan Pada Perkerasan Lentur (Studi Kasus Jalan Soekarno-Hatta Bandar Lampung)."

[2] P. \& H. A. \& S. D. Pratomo, "Aspal Modifikasi dengan Penambahan Plastik Low Liniear Density Poly Ethylene (LLDPE) Ditinjau dari Karakteristik Masrhall dan Uji Penetrasi pada Lapisan Aspal Beton (AC-BC)."

[3] I. Susanto, N. Suaryana, B. Litbang Perkerasan Jalan, P. Litbang Jalan, and K. Pekerjaan Umum dan Perumahan Rakyat, "Evaluasi Kinerja Campuran Beraspal Lapis Aus (AC-WC) dengan Bahan Tambah Limbah Plastik Kresek," 2019.

[4] Suherman, "PENGARUH POLIMER EVA (ETHYLENE VINYL ACETATE) TERHADAP KINERJA CAMPURAN LAPIS ANTARA (AC-BC)."

[5] M. Ardian, A. Setyawan, and D. Sarwono, "PENGARUH BITUMEN MODIFIKASI POLIMER ETHYLENE VINYL ACETATE (EVA) PADA ASPHALT CONCRETE TERHADAP KARAKTERISTIK MARSHALL,” 2016.

[6] W. Wantoro, D. Kusumaningrum, H. Setiadji, and W. Kushardjoko, "PENGARUH PENAMBAHAN PLASTIK BEKAS TIPE LOW DENSITY POLYETHYLENE (LDPE) TERHADAP KINERJA CAMPURAN BERASPAL."

[7] T. Suroso \& Wasiah, "PENGARUH PENAMBAHAN PLASTIK LDPE ( LOW DENSITY POLY ETHILEN ) CARA BASAH DAN CARA KERING TERHADAP KINERJA polyethylene ) by dry process and wet process to characteristic," pp. 1-17.

[8] Subarkah, "PENGARUH TIPE GRADASI AGREGAT TERHADAP SIFAT BETON ASPAL DENGAN BAHAN PENGIKAT ASPAL PERTAMINA PEN 60/70 DAN ASPAL STARBIT E-55 CAMPURAN AC-WC."

[9] Sumiati, Mahmuda, and Puryanto, "Bina Marga revisi 3, 2010) dan Pedoman Spesifikasi Teknis Campuran Beraspal dengan Asbuton,” Kementerian Pekerjaan Umum, 2013. 